Universidad de Lima

Escuela de Posgrado

Maestría en Derecho Empresarial

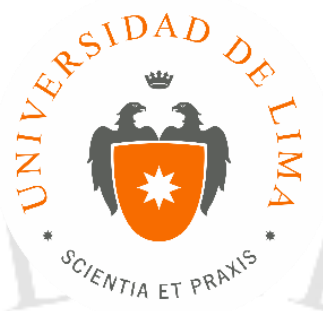

\title{
RESPONSABILIDAD DE LA EMPRESA DERIVADA DE ACCIDENTES DE TRÁNSITO CON DAÑOS PERSONALES
}

Trabajo de investigación para optar el Grado Académico de Maestro en

Derecho Empresarial

Gonzalo Enrique Castro Huayna

Código 20011043

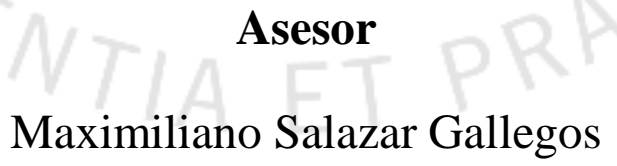

Lima - Perú

Mayo de 2017 


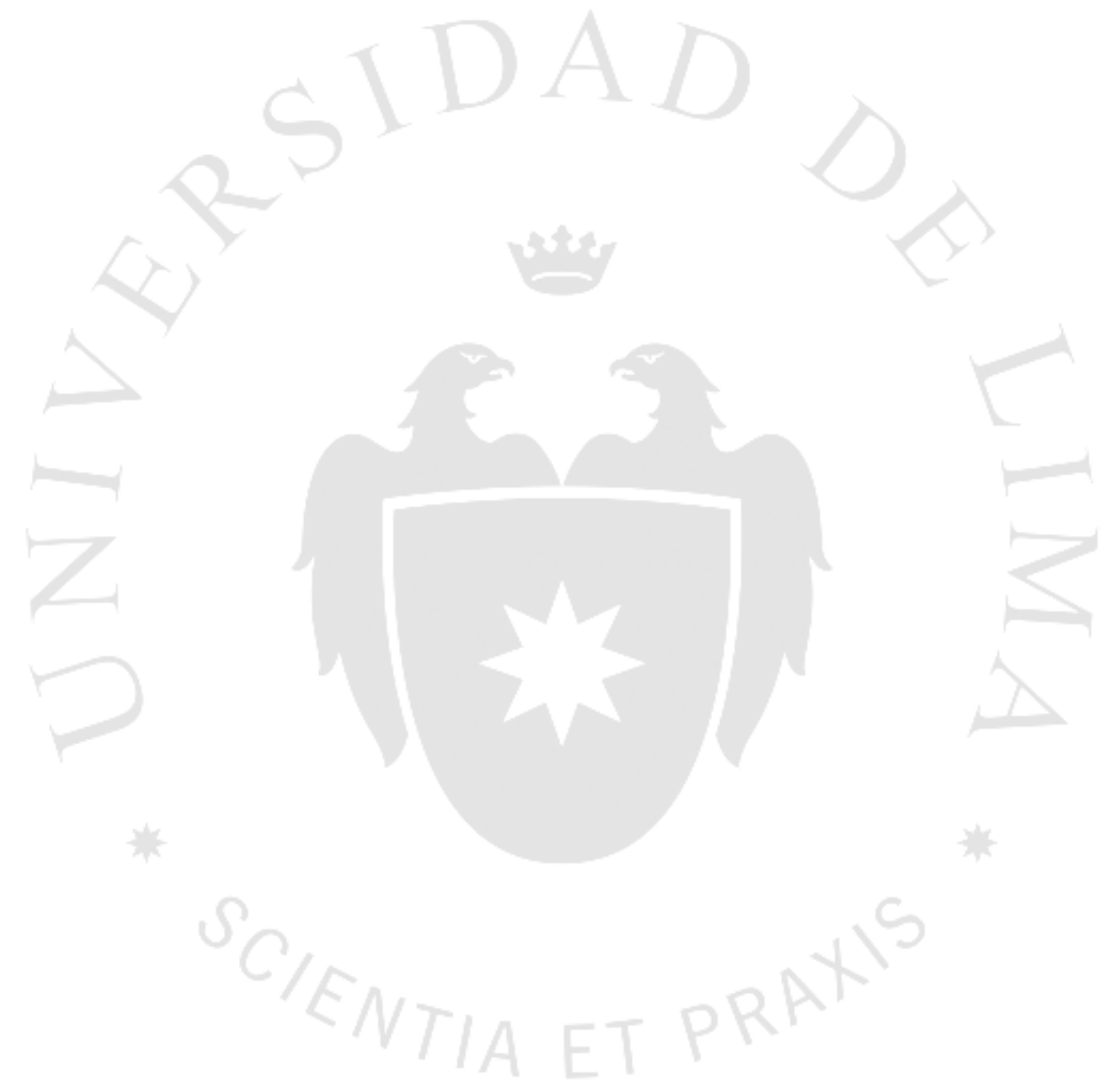




\section{RESPONSABILIDAD DE LA EMPRESA DERIVADA DE ACCIDENTES DE TRÁNSITO CON DAÑOS PERSONALES}




\section{TABLA DE CONTENIDO}

\section{CAPÍTULO I: RESPONSABILIDAD DE LA EMPRESA EN}

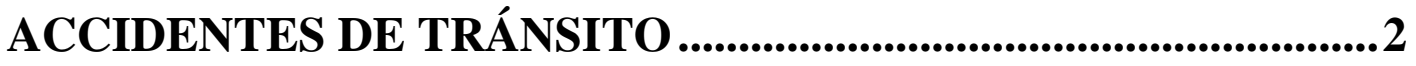

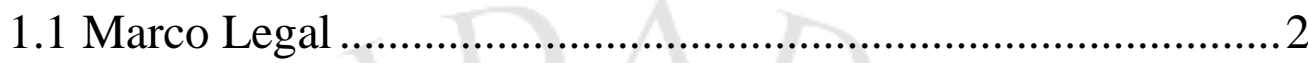

1.2 Configuración de un accidente de tránsito............................... 6

1.3 Fase preliminar de un accidente de tránsito con lesiones.........9

1.3.1 Investigación policial........................................................... 10

1.3.2Investigación a cargo del Ministerio Público. .......................... 16

1.4 Proceso penal por accidente de tránsito....................................18

2 CAPÍTULO II: CONTINGENCIA EMPRESARIAL FRENTE A LOS ACCIDENTES DE TRÁNSITO CON DAÑOS PERSONALES

21

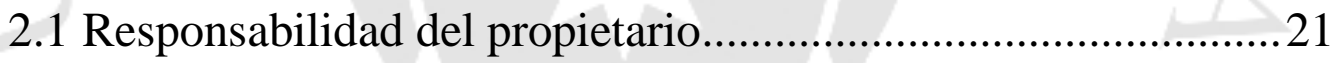

2.2 Responsabilidad del arrendatario financiero. ..........................24

2.3 Responsabilidad civil del dependiente....................................25

3 CAPÍTULO III: RESARCIMIENTO DEL DAÑO PERSONAL 30

3.1 Cuantificación del daño personal................................................30

3.2 Panorama sobre la cuantificación del daño moral en los casos de homicidio culposo derivado accidentes de tránsito ....................31

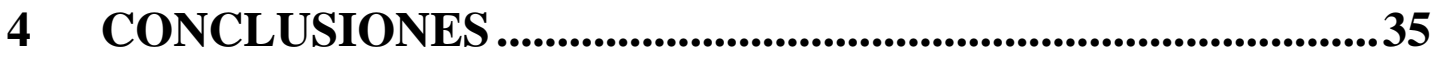

RECOMENDACIONES........................................................................37 


\section{BIBLIOGRAFÍA}

¡ERROR! MARCADOR NO DEFINIDO.

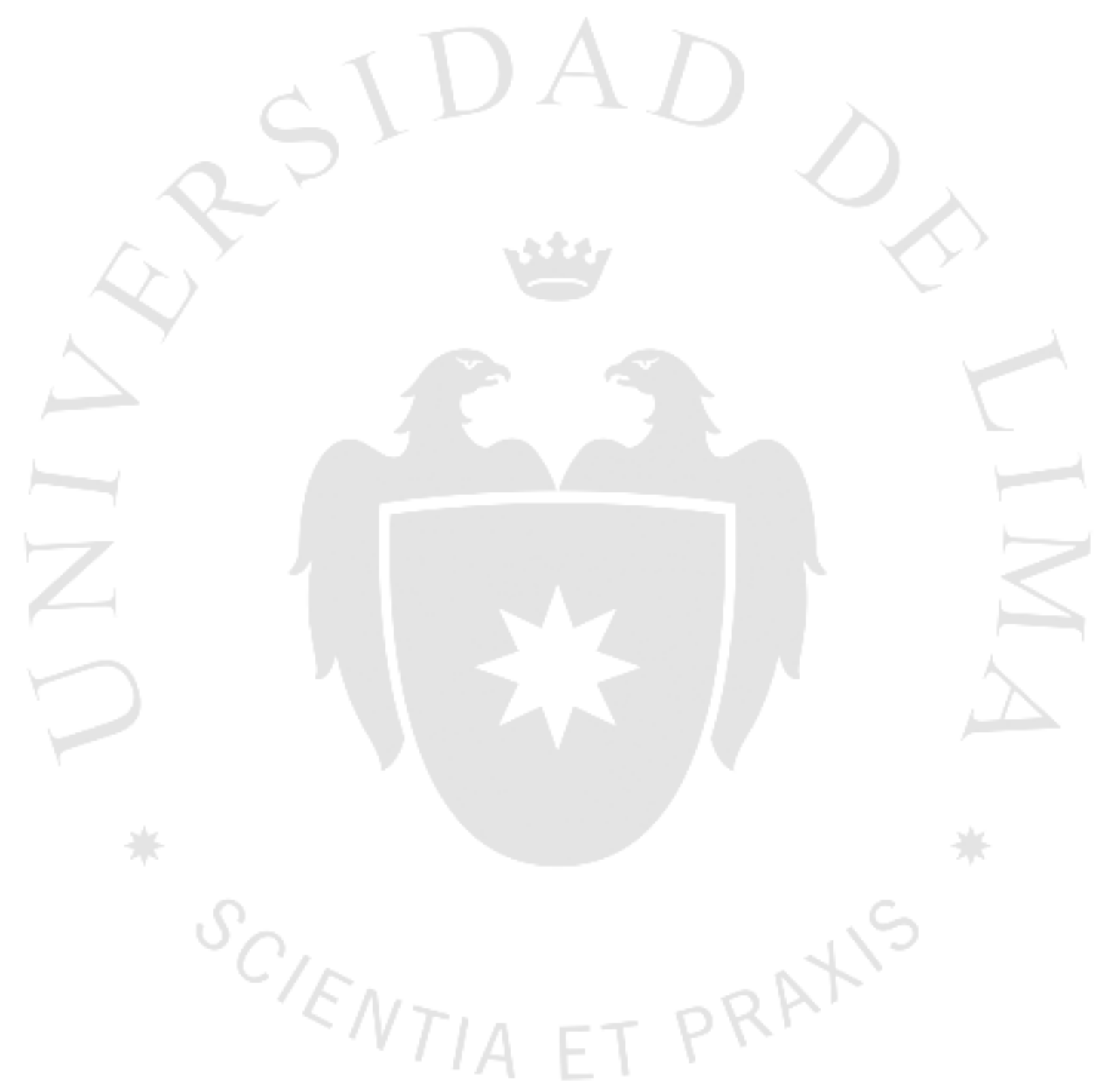




\section{INTRODUCCIÓN}

La actividad empresarial de una sociedad contempla riesgos en el giro de su negocio. Los accidentes laborales han encontrado en su regulación una solución tanto para la empresa y sus colaboradores ante un accidente en el trabajo. Sin embargo, no podemos decir lo mismo en los casos de accidentes de tránsito ocasionados con un vehículo automotor vinculado a la empresa. Corresponde cuestionar, qué sucede cuando un trabajador por medio de un vehículo empresarial ocasiona daños personales a terceros. Ante lo cual, nos corresponde cuestionar sobre el procedimiento o proceso en los cuales se verá sometida la empresa. Asimismo, si existen mecanismos para que la empresa como propietaria encuentre una solución a su obligación de resarcir el daño causado por sus dependientes. 


\section{CAPÍTULO I: RESPONSABILIDAD DE LA EMPRESA EN ACCIDENTES DE TRÁNSITO}

\subsection{Marco Legal}

Para definir un accidente de tránsito no necesitamos recurrir a diccionarios, la misma realidad nacional y noticias del día a día nos lo definen a diario como un suceso catastrófico, doloso y algunas veces como un hecho revisto de impunidad. Sin embargo, tenemos un marco legal diseñado para regular las sanciones, más no prevenciones, de los accidentes de tránsito.

El presente trabajo pretende desarrollar un análisis del panorama de la responsabilidad de la empresa frente a un accidente de tránsito, específicamente en donde se ha ocasionado daños personales. Por cuanto es en este escenario, a diferencia en donde solo se ocasionan daños materiales y estos daños pueden cuantificarse y son perfectamente resarcibles, se genera una contingencia para la empresa por el solo hecho de ser propietaria de un vehículo que ha participado en un accidente de tránsito. Lo cual supone elevación de costos operativos y de transacción. En la mayoría de casos, un accidente de tránsito puede suponer el inicio de un proceso penal donde la empresa será considerada en como tercero civilmente responsable.

Primero, debemos tener presente que según el (TUO del Reglamento Nacional de Transito aprobado mediante Decreto Supremo N 016-2009-MTC) (RNT en lo sucesivo), en su artículo 2, establece la definición de "accidente", señalando:

Accidente: Evento que cause daño a personas o cosas, que se produce como consecuencia directa de la circulación de vehículos.

Sin embargo, el RNT peruano no establece una definición concreta de lo que sería un accidente de tránsito. Tal como ocurre en el caso de Argentina, como DARAY (2001) señala: "[...] la actual ley 24.449 [...] en el capítulo V, art. 64, dice: "Se considera accidente de tránsito todo hecho que produzca daño en personas o cosas como consecuencia de la circulación." (p. 1). 
En primer lugar, tenemos que tener presente que frente a un accidente de tránsito con daños personales se configura hecho culposo, es decir un hecho sin intencionalidad, donde el procesado principal será el conductor de la unidad vehicular, y que con la utilización de un vehículo con motor se ocasiona daño. El accidente de tránsito se puede producir por una mala maniobra o impericia por parte del conductor, y en algunos casos puede darse la contribución del accionar de otra persona o la propia víctima. Por lo que no estamos frente a un ilícito penal doloso, ni mucho menos el supuesto de dolo eventual.

Pensemos un momento en el ciudadano Carlos Lescano quien maneja por la Avenida Arequipa en la ciudad de Lima, viene realizando su circulación a una velocidad moderada, y se detiene ante la luz de un semáforo en rojo. Mientras espera el cambio de luz, cruza la calle su exnovia con quien ahora es su nueva pareja. Carlos, en ese instante, al recordar y sentir el sufrimiento y aflicción por la reciente ruptura amorosa decide presionar el acelerador de su unidad de la empresa y los atropella. Ambos resultan con lesiones personales. Sin embargo, ante este hecho estaríamos frente a un delito doloso por cuanto existe intención y premeditación para ocasionar daño. Lo cual se condice con el hecho que quien ocasionó el daño tenía una vinculación con su víctima.

La controversia en este tipo de casos sería si la empresa por el solo hecho de ser propietaria de la unidad participante también será considerada como tercero civilmente responsable.

A priori, podemos señalar que será la autoridad competente será quien determinará la configuración del ilícito penal: doloso o culposo. Por otra parte, diferente sería el escenario en donde Carlos, por el nerviosismo e impericia hubiese presionado el pedal del acelerador en vez de presionar el pedal de freno frente a la pareja en cuestión. Por esta razón sería importante que el Reglamento Nacional de Tránsito hiciera la precisión que para la configuración de un accidente de tránsito se trata de "un evento casual". De esta manera los accidentes de tránsito se limitarían a eventos sin intencionalidad: dolo o el mencionado dolo eventual.

En se orden de ideas, se podría arribar a un concepto de accidente de tránsito como un evento casual en el cual participa por lo menos un vehículo automotor y con motivo de la circulación ocasiona daños materiales y/o personales. 
Por otra parte, tenemos el artículo $1^{\circ}$ del (Decreto Supremo Nº15-2013-MTC, publicado el 15 noviembre 2013, Reglamento Nacional de Responsabilidad Civil y Seguros Obligatorios de tránsito), cuyo texto es el siguiente:

Accidente de Tránsito.- Evento súbito, imprevisto y violento (incluyendo incendio y acto terrorista) en el que participa un vehículo automotor en marcha o en reposo (detenido o estacionado) en la vía de uso público, causando daño a las personas, sean ocupantes o terceros no ocupantes de vehículo automotor, que pueda ser determinado de una manera cierta.

Antes de comentar el mencionado artículo, es necesario tener presente que los seguros obligatorios de accidentes tránsito (SOAT en lo sucesivo) otorgan la cobertura para la atención médica de las víctimas de accidentes de tránsito hasta la suma equivalente a 5 Unidades impositivas Tributarias (UIT). Además, su ámbito de aplicación es en las vías de uso público. De esta manera, conforme al artículo en cuestión se restringe su aplicación para las vías de uso público. Es decir, si sucede un accidente de tránsito con daños personales en una vía privada como por ejemplo: un estacionamiento privado de un centro comercial, una fábrica o una mina, no habrá cobertura del siniestro. Cabe resaltar que de manera supletoria se pueden aplicar las reglas de circulación de tránsito para un estacionamiento privado, pero no podría aplicarse la póliza de seguro obligatorio de accidentes de tránsito (SOAT) para la atención de un agraviado en un accidente de tránsito en un estacionamiento privado. Lo cual no es óbice, para que los intervinientes puedan sufragar los costos de atención médica o activar la póliza de responsabilidad civil contra terceros, contratada previamente.

Cabe resaltar que la cobertura del SOAT es automática a las lesiones y siniestros ocurridos con motivo de la circulación, es decir, que para su utilización no se requiere que se determine la responsabilidad del causante en la investigación policial. Solo se requiere que los participantes realicen la denuncia policial correspondiente para efectos de iniciar el trámite frente a la compañía aseguradora.

Una vez más, con respecto a la responsabilidad de los accidentes de tránsito, podemos señalar que la responsabilidad es objetiva, por creación del riesgo, con la utilización de un vehículo automotor. La responsabilidad en un accidente de tránsito se funda en el Código Civil (CC en lo sucesivo):

Artículo $1970^{\circ}$.- del Aquel que mediante un bien riesgoso o peligroso, o por el ejercicio de una actividad riesgosa o peligrosa, causa un daño a otro, está obligado a repararlo. 
Del mismo modo, en caso que el accidente se haya suscitado con la intervención de un dependiente o colaborador de una empresa, tenemos como resultado que la responsabilidad será solidaria. Conforme lo señala el CC.:

Artículo $1981^{\circ}$.- Aquél que tenga a otro bajo sus órdenes responde por el daño causado por éste último, si ese daño se realizó en el ejercicio del cargo o en cumplimiento del servicio respectivo. El autor directo y el autor indirecto están sujetos a responsabilidad solidaria

Además, tenemos que para los casos de accidentes de tránsito, la (Ley General de Transporte y Tránsito Terrestre - Ley 27181), señala cual será el criterio de responsabilidad:

Artículo 29.- De la responsabilidad civil La responsabilidad civil derivada de los accidentes de tránsito causados por vehículos automotores es objetiva, de conformidad con lo establecido en el Código Civil. El conductor, el propietario del vehículo y, de ser el caso, el prestador del servicio de transporte terrestre son solidariamente responsables por los daños y perjuicios causados.

Sin embargo, en cuanto al tema del presente trabajo, nos compete cuestionar hasta donde resulta responsable la empresa como propietaria del vehículo participante en un accidente de tránsito. Asimismo, corresponde cuestionar el marco legal señalado con relación a los casos donde el propietario registral, no es el verdadero propietario, o si el prestador de servicios de transporte terrestre corresponde a una empresa que brinda servicio de taxi por medio de una aplicación en Internet. Son temas que desarrollaremos en su oportunidad. Pero sin lugar a dudas, lo más cuestionado en lo que se refiere a la regulación del tránsito no hay mucho que discutir, el problema radica en la forma como conviven diversas regulaciones para un mismo hecho y un procedimiento de investigación policial que resulta muy cuestionable, si se tiene en consideración que para determinar la responsabilidad se basa en criterios de culpabilidad, es decir responsabilidad subjetiva.

No podemos dejar de reiterar que para la configuración de un accidente de tránsito no se requiere que la circulación de un automotor se realice en la vía pública. Tal es el caso de la ciudadana Lourdes Gricelda Álvarez Rubio contra la empresa Neptunia sociedad Anonima que mediante sentencia de la Corte Suprema nos relata:

[...] la demandante señala que el nueve de abril de dos mil cuatro, aproximadamente a las 19:20 horas, su concubino Robert Salazar Marín se encontraba cumpliendo labores de vigilancia dentro del establecimiento de la empresa Neptunia Sociedad Anónima, 
ubicado en la Avenida Argentina $\mathrm{N}^{\circ} 2085$ - Callao, en condición de trabajador de la Empresa de Servicios de Vigilancia y Seguridad Plainvest Sociedad Anónima. En ese momento, encontrándose en disposición de abrir la puerta de metal del referido local, fue arrollado por la máquina porta contenedor $\mathrm{N}^{\circ} 07$, marca Taylor, conducida por el señor Luis Cruz Cutipa (Chofer dependiente de la empresa Neptunia Sociedad Anónima), quien, a causa de su imprudencia, provocó la muerte de su concubino. (Casación 1852 2015 - Callao, 2016)

La sentencia citada, nos da un claro ejemplo que los accidentes de tránsito pueden suscitarse en un estacionamiento privado, y no necesariamente por medio de un automóvil o vehículo matriculado, donde se registre la propiedad de la empresa. En el presente caso el accidente de tránsito se ocasiona con una Maquina porta contenedor Marca Taylor que era conducido por un colaborador de la empresa. Por lo que en el presente caso estamos frente a un claro ejemplo de la responsabilidad de la empresa por un hecho ocasionado por un dependiente o trabajador. No obstante lo anterior, podría cuestionarse si el presente accidente se trata un accidente laboral, el cual pudo haberse llevado en sede laboral. Sin embargo, de acuerdo a la normativa citada podríamos concluir que para la configuración de un accidente de tránsito se requiere la participación de un vehículo con características para la circulación en la vía pública.

Finalmente, nuestro comentario sobre el artículo $1^{\circ}$ del (Decreto Supremo $N^{\circ}$ 015-2013MTC, publicado el 15 noviembre 2013, Reglamento Nacional de Responsabilidad Civil y Seguros Obligatorios de tránsito) es que un acto terrorista no debería ser contemplado en la legislación como un accidente de tránsito, por cuanto un hecho de tales características no debería activar la cobertura de la póliza SOAT y el seguro de responsabilidad contra terceros, por cuanto estos están limitados para la cobertura de siniestros sucedidos como accidentes de tránsito, y el daño ocasionado por un acto terrorista le correspondería reparar a quienes resulten responsables. Tanto las compañías de seguros, y la empresa propietaria no tendría por qué asumir una carga y/o obligación por el uso de los seguros de responsabilidad civil contra terceros en este mencionado supuesto.

\subsection{Configuración de un accidente de tránsito}

Un accidente de tránsito se configura cuando se produce el despiste de una unidad de tránsito, en este caso un vehículo automotor, también cuando se ocasiona daño mediante 
un impacto entre dos a más vehículos automotores. Asimismo, cuando una unidad de tránsito impacta a una persona o más personas que circulan como peatones. Siendo en estos casos, el peatón considerado como una unidad de tránsito. En ese orden de ideas, no podríamos estar frente a un accidente de tránsito en un hecho accidental donde no se logra consolidarse un impacto. Como por ejemplo, nuestro colaborador Carlos Lescano al circular por la Avenida Comandante Espinar en sentido Sur a Norte, casi al llegar al Ovalo Gutiérrez, ante la presencia de un peatón que se encontraba cruzando en sentido Oeste - Este, este logra frenar y evitar el impacto, el peatón ante el sonido por la violenta aplicación de los frenos se asusta. Inmediatamente, el peatón solicita la presencia de la policía. Al instante, en el lugar aparece un efectivo policial que ha presenciado el evento y le indica a los ciudadanos que no se ha producido un accidente de tránsito por cuanto el vehículo directamente no ha ocasionado daño al peatón. Por lo que en caso que la caída haya ocasionado lesiones, el caso debería derivarse a la sección delitos o faltas contra la persona de la Comisaría. Por lo que no siendo este un accidente de tránsito, la póliza SOAT no se activará.

Una vez ocurrido un accidente de tránsito, ya sea en la vía pública o vía privada, de acuerdo al artículo 7 del RNT, la Policía Nacional del Perú es competente para investigar y denunciar ante las autoridades las infracciones al reglamento por parte de los participantes en un accidente de tránsito. En ese sentido, tenemos que si en la investigación policial se determina que un conductor ha ocasionado daños personales con inobservancia de las reglas de tránsito se comunicará a la autoridad competente el hecho. Como veremos en otro apartado la competencia se determinará en el grado de incapacidad del lesionado o si se trata de un accidente con lesiones y/o con consecuencia fatal.

La investigación policial se inicia mediante un parte, u ocurrencia de tránsito, que es elaborado por el efectivo policial que interviene en el evento o en el lugar del accidente. En el parte policial se limita a señalar las personas implicadas y unidades de tránsito intervinientes en el accidente. De la misma manera se precisa el lugar, la calle o avenida donde ha ocurrido el evento, esto para determinar la jurisdicción policial. En el caso que se hayan producido lesiones, el efectivo policial debe identificar a las personas lesionadas y el centro de salud a donde son trasladados para su atención médica. Resulta importante para la investigación que se consigne el diagnostico preliminar de cada lesionado. En el caso que haya un fallecido, solo corresponde identificar a la persona y notificar al Ministerio Público para las diligencias correspondientes al cadáver. La PNP es 
competente desde el momento que ha ocurrido el accidente hasta la culminación de la investigación policial, velando por las obligaciones de los conductores participando de acuerdo al artículo $275^{\circ}$ del RNT. Entre las cuales destacan:

Artículo 275.- Obligaciones del conductor implicado en un accidente de tránsito. El conductor implicado en un accidente de tránsito debe:

1) Detener en el acto el vehículo que conduce, sin obstruir ni generar un nuevo peligro para la seguridad del tránsito, permaneciendo en el lugar hasta la llegada del Efectivo de la Policía Nacional del Perú, asignado al control del tránsito, interviniente.

2) Suministrar sus datos y presentar los documentos que le requiera el Efectivo de la Policía Nacional del Perú interviniente.

3) En caso de accidentes con víctimas, dar el auxilio inmediato a las personas lesionadas, hasta que se constituya la ayuda médica.

4) Señalizar adecuadamente el lugar, de modo que se evite riesgos a la seguridad de los demás usuarios de la vía;

5) Evitar la modificación o desaparición de cualquier elemento útil a los fines de la investigación policial.

6) Denunciar inmediatamente la ocurrencia del accidente de tránsito ante la Comisaría de la Policía Nacional del Perú de la jurisdicción; y someterse al dosaje etílico.

7) Comparecer y declarar ante la Autoridad, cuando sea citado.

Nuevamente, tenemos a nuestro colaborador diligente Carlos Lescano quien ahora al transitar por la Avenida Javier Prado en sentido Oeste con el vehículo de propiedad de la empresa impacta a un vehículo que se encontraba delante de su unidad. Ocasionando lesiones personales en los pasajeros de la unidad de taxi que lo antecedía. Al parecer resultan lesiones leves por el ligero golpe, pero ambos conductores se preocupan de la salud de los ocupantes. Por lo que solicitan auxilio y la intervención policial. Cumpliendo de esta manera lo señalado en los artículos 274 y 275 del RNT. Sin embargo, una vez que la Policía interviene a los conductores, Carlos Lescano entrega sus documentos (Documento de identificación, Licencia de Conducir, Certificado de póliza SOAT). Sin embargo, el otro conductor quien aparentemente no cuenta con permiso para realizar el servicio de taxi, no presenta sus documentos y se niega a acudir a la comisaria por cuanto 
aduce que el tiempo es lo que menos le sobra. Ante lo cual, el efectivo policial una vez que lo identifica decide elaborar un parte policial por resistirse y desobedecer a la autoridad policial. (Artículo 368 del Código Penal (Decreto Legislativo $\mathrm{N}^{\circ}$ 635, 1991)). Ante lo cual, Carlos Lescano pese a considerarse responsable del evento prosigue con el trámite policial.

Las obligaciones de los conductores que participan en un accidente de tránsito son claras y su evidente desacato puede conllevar a configurar otros delitos o ilícitos penales sancionados por ley. Suele ocurrir que en un evento como puede ser un accidente de tránsito que el conductor decida abandonar el lugar y a sus posibles víctimas. Ante lo cual, ya nos encontramos ante un supuesto de exposición de personas al peligro. (Artículo 126 del Código Penal (Decreto Legislativo $N^{\circ}$ 635, 1991)). No obstante que se haya cometido el ilícito penal invocado, el SOAT de la unidad participante permitirá la cobertura del siniestro en lo que respecta a los daños personales ocasionados. Sin embargo, las pólizas voluntarias de responsabilidad civil frente a terceros este tipo de evento tiene limitaciones por cuanto estamos frente a un ilícito penal doloso. De la misma manera sucede con la conducción en estado de ebriedad. (Artículo 274 del Código Penal (Decreto Legislativo $\left.\mathrm{N}^{\circ} 635,1991\right)$ ). Ante estos hechos, si han sido realizados con un vehículo de propiedad de la empresa, la misma será considerada tercero civilmente en los casos de los delitos de Lesiones Culposas, Homicidio culposo y Exposición de personas al peligro.

\subsection{Fase preliminar de un accidente de tránsito con lesiones.}

Una vez que el efectivo policial quien intervino en el lugar de los hechos pone a disposición a los conductores en la comisaría de la jurisdicción a la cual le corresponde el accidente de tránsito, el caso será llevado por el efectivo policial encargado de la Sección de Investigación de Accidentes de Tránsito (SIAT) quien recibe el parte policial y de acuerdo al diagnostico preliminar de los lesionados comunicará al Ministerio Público para su intervención. En estos casos la Fiscalía solo es competente en caso que haya indicios suficientes de haberse configurado un delito de lesiones culposas agravadas $\mathrm{u}$ homicidio culposo. En caso que las lesiones sean leves, no se comunica al Ministerio Público, por cuanto puede haberse cometido el delito por faltas contra la persona. Siendo en este caso competente el Juez de paz de acuerdo a la (Ley 27939). 
Cabe resaltar que la diferencia entre lesiones leves y lesiones graves radica en el tiempo de incapacidad. Conforme lo señala el Código Penal (Decreto Legislativo $\mathrm{N}^{\circ} 635$, 1991):

Artículo 121.- Lesiones graves.

[...]Se consideran lesiones graves:

1. Las que ponen en peligro inminente la vida de la víctima.

2. Las que mutilan un miembro u órgano principal del cuerpo o lo hacen impropio para su función, causan a una persona incapacidad para el trabajo, invalidez o anomalía psíquica permanente o la desfiguran de manera grave y permanente.

3. Las que infieren cualquier otro daño a la integridad corporal, o a la salud física o mental de una persona que requiera treinta o más días de asistencia o descanso, según prescripción facultativa.

Por otra parte, tenemos

Artículo 122.- Lesiones leves

El que causa a otro un daño en el cuerpo o en la salud que requiera más de diez y menos de treinta días de asistencia o descanso, según prescripción facultativa, será reprimido con pena privativa de libertad no mayor de dos años y con sesenta a ciento cincuenta días-multa.

Cabe resaltar que de acuerdo al numeral 2 del artículo $440^{\circ}$ del Código Penal (Decreto Legislativo $\left.\mathrm{N}^{\circ} 635,1991\right)$, señala que en los delitos por faltas, solo responderá el autor, por lo que la empresa propietaria de la unidad participante, no podría verse involucrada y no podría ser declarada tercero civilmente responsable en un proceso por faltas contra la persona. Por lo contrario, en un proceso penal, por lesiones culposas agravadas y homicidio culposo la empresa será considerada como tercero civilmente responsable. Por lo que podemos inferir que en los casos de faltas contra la persona, nuestro colaborador Carlos Lescano no tendrá problemas con su empleador.

\subsubsection{Investigación policial.}

La investigación policial requiere que los vehículos participantes sean evaluados por un perito policial, el cual cumple con emitir un resultado de peritaje de daños. Asimismo, para continuar con la investigación se necesita el certificado médico legal de las personas 
lesionadas, o en su caso, el certificado de necropsia; así mismo, la declaración de parte de cada uno de los intervinientes en el accidente de tránsito. A su vez se requiere los elementos y diligencias que el efectivo policial encargado de la Sección de Investigación de Accidentes de Tránsito (SIAT) considere necesario, como por ejemplo, croquis del lugar del accidente, videos, fotografías y declaración de testigos. En algunos casos el reporte de rastreo satelital para efectos de corroborar la velocidad de la unidad investigada. Siendo todos estos elementos necesarios para verificar si existen indicios suficientes de la configuración de un ilícito penal.

La investigación policial concluye con un informe en donde se señalará el grado de participación de cada participante. Así como del análisis del peritaje de daños de las unidades de tránsito que han participado se podría establecer la forma y circunstancia del evento. De esta manera, el efectivo policial encargado de la investigación, podrá establecer las infracciones al reglamento por parte de conductores y peatones. A pesar que la regulación de tránsito señala que la responsabilidad civil es objetiva, la valoración de la responsabilidad se efectúa de manera personal y subjetiva, en grados de culpa. Tal es así que en la actualidad, suele atribuirse a los conductores la infracción contenida en el inciso b del artículo 90 del RNT, que señala:

Artículo 90.- Reglas generales para el conductor.

Los conductores deben:

$[\ldots]$

b) En la vía pública: Circular con cuidado y prevención.

De esta manera, podemos ser testigos de informes policiales en los cuales se consigna como causa frecuente de un accidente de tránsito el hecho de conducir "sin cuidado y prevención”. Otra vez, tenemos a nuestro ciudadano promedio Carlos Lescano quien conduce un día lunes no festivo por la Avenida La Marina, al promediar las ocho de la noche transita por el carril izquierdo de la vía con dirección a San Isidro. En el separador central de la vía existen unos montículos de arena con pasto sembrado, así como algunos arbustos. Luego de pasar estos sin mayor problema, escucha un golpe en la carrocería. Decide detenerse y se da con la sorpresa que ya no cuenta con el espejo retrovisor lateral izquierdo. Supone que algo ha rozado con la carrocería, y cuando desciende de su unidad observa que había un hombre caído sobre el pavimento donde no hay un crucero peatonal. 
De acuerdo a los criterios de imputación objetiva, Carlos Lescano debería acreditar la ruptura del nexo causal, en este caso por el hecho propio de la víctima al cruzar por un lugar no autorizado para el cruce de peatones. Sin embargo, luego de la investigación policial se da con la sorpresa que la responsabilidad ha sido evaluada en factores subjetivos, siendo el factor determinante para la generación del accidente el accionar intempestivo por parte del peatón, quien se encontraba en estado de ebriedad, habría cruzado la avenida La Marina sin medir el riesgo y peligro que impone la vía. Sin embargo, la policía también ha determinado que existe un factor contributivo por parte de Carlos Lescano al conducir su vehículo sin el debido cuidado y prevención para evitar el accidente. Por cuanto, al transitar por una zona de discotecas y pubs que implican un alto tránsito de peatones, debió manejar a una velocidad prudente que le permita evitar el accidente.

En estos casos, es lamentable que la policía en vez de señalar que se circulaba a una excesiva velocidad, termine aplicando (el inciso b del art. 90 del RNT). Esto como una especie de cajón de sastre. Somos de la opinión que el Reglamento Nacional de tránsito con este tipo de normas, no hace más que ser más beneficioso para el peatón imprudente. Esto sucede por cuanto los investigadores de tránsito no cuentan con dispositivos que les permita medir la velocidad de manera objetiva. Siendo las huellas de frenada solo una prueba para medir el tiempo de reacción por parte del conductor, pero no es un elemento objetivo que determine una excesiva velocidad. Por otra parte, resultaría contradictorio que en la zona no exista una regulación de velocidad, en la cual se establezca un límite máximo y que el hecho de superar este límite implicaría la infracción al reglamento. Peor aún resulta incongruente que la investigación sea trasladada a supuestos subjetivos como el conocimiento previo de la zona para tomar mayores precauciones. No resultaría valido este razonamiento, peor aún si se trata de un día lunes donde la afluencia de clientes de los locales nocturnos es nula o diminuta. Este tipo de análisis implicaría por lo menos, en sede penal, demandaría la recreación de los hechos en el lugar del evento y de esta manera hacer una medición objetiva de la afluencia de los peatones que cruzan la vía por un lugar no autorizado.

Es por estas razones, donde existen daños recíprocos. Tanto en la unidad y en el peatón para efectos de la investigación resulta importante, como lo señala BERDEJO (2007) no resulta suficiente aplicar una regla de responsabilidad objetiva. 
Frente, a este resultado [...] se podría optar por dos caminos de solución: i) aplicar a estos casos una regla de responsabilidad subjetiva, pues en aquellos casos donde las dos partes del accidente están en capacidad de prevenirlo (prevención bilateral) resulta más eficiente aplicar la regla de responsabilidad subjetiva a fin de lograr un efecto deterrence, o ii) Determinar quién fue el causante del accidente a través de una indagación de la relación de causalidad (relación causa efecto entre la conducta del agente y la producción del daño a la víctima), con prescindencia de la noción de criterio de imputación, aún cuando nos encontremos en un supuesto de responsabilidad objetiva basado en riesgo. (p. 47).

De lo anterior, entendemos que la investigación policial funda su investigación en el primer supuesto. Por ello mide la responsabilidad en virtud de la conducta de los participantes, y sanciona conforme al reglamento las conductas contrarias al reglamento. Por lo que en un escenario donde hay dos participantes, se entenderá que tendrá más responsabilidad aquel participante que posea más infracciones al reglamento por el accidente de tránsito. Una especie de Score o tablero de faltas. Volviendo a nuestro caso, el peatón, a quien atropelló Lescano habría infringido los siguientes artículos del RNT:

Artículo 68.- Cruce de la calzada.

En intersecciones señalizadas, los peatones deben cruzar la calzada por la zona señalizada o demarcada especialmente para su paso. En las intersecciones no señalizadas, el cruce debe realizarse en forma perpendicular a la vía que cruza, desde una esquina hacia otra, y de ser el caso, atendiendo las indicaciones de los Efectivos de la Policía Nacional del Perú. Debe evitar cruzar intempestivamente o temerariamente la calzada.

Artículo 74.- Regla general para el cruce.

Para cruzar la calzada en cualquiera de los casos descritos en los artículos anteriores, los peatones deben hacerlo caminando, en forma perpendicular al eje de la vía, asegurándose que no exista peligro.

Artículo 276.- Presunciones de responsabilidad respecto del peatón.

El peatón goza del beneficio de la duda y de presunciones a su favor, en tanto no incurra en graves violaciones a las normas del tránsito, como cruzar la calzada en lugar prohibido; pasar por delante de un vehículo detenido, parado o estacionado habiendo tránsito libre en la vía respectiva; transitar bajo la influencia del alcohol, drogas o estupefacientes; cruzar intempestivamente o temerariamente la calzada; bajar o ingresar repentinamente 
a la calzada para intentar detener un vehículo; o subir o bajar de un vehículo en movimiento o por el lado izquierdo.

Ahora, si el impacto no se realizó con la parte frontal del vehículo, sino por el contrario se ocasionó con la parte lateral de la unidad de tránsito, estaríamos ante la configuración de un atropello por encontronazo. En donde la responsabilidad radica en el hecho que el conductor por la acción sorpresiva del peatón, no pudo prever que sucediera un impacto, sobre todo, si el peatón se acerca en forma perpendicular al vehículo hasta impactarlo. En este caso, pese a haberse señalado que Carlos Lescano había contribuido a la generación del accidente, se le declaró inocente en el proceso por delito de lesiones culposas agravadas por cuanto se habría configurado una auto exposición al peligro por parte del propio peatón.

Por su parte, Daray (2001) nos refiere un caso en la jurisprudencia Argentina:

75. El sitio en que el cuerpo de la actora impactó contra el vehículo es claramente demostrativo de que no se trató de un embestimiento frontal de éste, sino que la accionante intercepto su paso, obviamente debido a su distracción, sumada a las condiciones de visibilidad escasa, que imponían un mayor cuidado. (p. 234).

Por otra parte, para este tipo de casos, Bramont - Arias Torres (2002) nos señala:

En los delitos imprudentes, no habrá imputación de conducta si es la victima la que, con su comportamiento, contribuye de manera decisiva a la realización del riesgo permitido, y este no se realiza en el resultado. Se trata de un caso de imputación a la víctima y no al autor. En efecto si el suceso realizado de modo conjunto es atribuido al ámbito de responsabilidad de la víctima, no puede ser típica la conducta del autor. Se trata de los supuestos en los que es la víctima y no el autor, quien infringe el deber de cuidado (autopuesta en peligro, ámbito de competencia o responsabilidad). (p. 233)

En un caso similar, la $25^{\circ}$ Fiscalía Penal Provincial de Lima, en la investigación 3502012 del cinco de junio del dos mil doce, ha señalado:

Como es de verse del Peritaje Técnico de Constatación de daños [..], los daños constatados en el vehículo están en el guardafango posterior derecho tercio anterior superior hundido, de lo que se infiere que el impacto del peatón ha sido en la parte posterior lateral derecho del vehículo [...]. 
En el atestado [...] se establece que la peatón trató de cruzar la calzada sin adoptar las medidas de seguridad a fin de salvaguardar su integridad física y por un lugar no apropiado; y que se encontraría incursa en el artículo 68 del Texto único Ordenado del Reglamento Nacional de Tránsito [...]

[De la revisión de los actuados se tiene que la actitud imprudente de la supuesta agraviada, no le permitió al denunciado tener el tiempo ni el espacio suficiente para maniobras evasivas que pudiera evitar la colisión, el factor predominante fue la acción imprudente de la peatón, la que de no haberse realizado hubiera eliminado la posibilidad del accidente, en tal sentido ella habría aumentado el riesgo permitido.

De la misma manera, razona la Corte Superior en la (Casación 2288-2013-Huara, 2014), al señalar:

[...] Tercero.- Que en el presente caso la Sala Superior ha determinado la ruptura del nexo causal contemplada por el artículo 1972 del Código Civil que prescribe que el imputado como autor no es responsable de los daños si estos constituyen consecuencia de caso fortuito, fuerza mayor, de hecho determinante de tercero o de la imprudencia de quien padece el daño debiendo anotarse que para que se configure la fractura causal el autor de una determinada conducta no debe ser el causante del daño imputado al mismo pues éste es consecuencia de otra causa librándose al exonerarlo de responsabilidad a efectos de la reparación por haber acreditado que el daño causado fue consecuencia no de su conducta sino de una causa ajena a él que no puede ser la propia imprudencia de la víctima debiendo la parte demandada demostrar que el daño causado fue consecuencia de la conducta de la propia víctima y no por la conducta del presunto autor.

Cuarto.- Que, sobre el particular la Sala Superior señala que las conclusiones que se consignan en el documento denominado Opinión Técnica número 07-2009-DEPIATPNP/UIAT emitida por la Unidad de Investigación de Accidentes de Tránsito de la Policía Nacional del Perú corriente a fojas ciento noventa y dos respecto a la acción del conductor de la UT-2 sobre el exceso de confianza y la conducción a una velocidad no razonable resultan apreciaciones cargadas de subjetividad pues no sólo no se han determinado a qué velocidad se desplazaba el vehículo para estimar lo peligroso que a su entender representa su circulación toda vez que no se señala cuál era la velocidad adecuada que debió utilizar y cuál no representaba un peligro alegando por ende que en dicho informe existe una apreciación carente de objetividad al pretender sustentar una hipótesis que no ha sido debidamente contrastada más aún si de los actuados no puede determinarse en que [SIC] situación era imposible que la UT-2 infringiera daño alguno ya que aún cuando la velocidad fuera de quince o veinte kilómetros por hora la colisión 
del vehículo UT-1 contra la UT-2 podía sufrir el mismo daño dada la diferencia de sus estructuras siendo uno de ellos automotor y por tanto seguir representando peligro por lo que las estimaciones del informe resulta siendo imprecisas y siendo que menor quien embistió con su bicicleta al vehículo mayor puede reputarse su conducta como imprudente. [...]

Por estas razones, somos de la opinión que los informes policiales al señalar que el accidente de tránsito se ha ocasionado por un exceso de confianza y que la conducción se realizó a una velocidad no razonable suponen una carga de subjetividad. Lo cual ocasiona que el informe policial sea evaluado a nivel fiscal y judicial como un medio de prueba. Por lo que en estos casos, se recomienda concurrir al proceso con un peritaje de parte, con el cual se pueda contrarrestar el valor probatorio del informe policial.

Finalmente, en los casos que la fiscalía encuentre que no existen indicios razonables para formalizar denuncia, podría determinar el archivo de la investigación en atención a que las lesiones se ocasionaron por el accionar de la misma víctima. Con lo cual podría concluir la contingencia penal.

\subsubsection{Investigación a cargo del Ministerio Público.}

Una vez que la policía comunica al Ministerio Público sobre la ocurrencia de un ilícito penal como consecuencia de un accidente de tránsito, el representante del Ministerio Público podría disponer la custodia del vehículo participante en el accidente de tránsito. Por lo general, la puesta en custodia se confunde con la figura de embargo, pues en esta etapa del procedimiento, el juez penal aún no tiene competencia si no se ha formalizado la denuncia correspondiente, por lo que el juez sería el único que podría disponer el embargo. En ese sentido, se recomienda que en estos casos el representante de la empresa propietaria del bien solicite la devolución en atención a que se ha cumplido con el peritaje técnico policial de la unidad. Siendo esta, la única actividad o examen que se realiza a la unidad de tránsito. Por lo que mal haría el fiscal en someter a una unidad que es patrimonio de la empresa que permanezca internada sin motivación suficiente. Por cuanto si lo que se pretende es garantizar el cumplimiento del pago de una reparación civil. Esta puede sustituirse con presentar documentos de un seguro voluntario de responsabilidad civil o el depósito de dinero en una cuenta a favor del agraviado. 
En caso que el Ministerio Público encontrarse indicios razonables de un ilícito penal como consecuencia de un accidente de tránsito, bien podría declarar la ampliación de la investigación para realizar mayores diligencias para el esclarecimiento de los hechos o proseguir con la audiencia de aplicación de Principio de Oportunidad o Acuerdo reparatorio.

Lo importante es que en esta etapa procesal para nuestro estudio, es que en atención al artículo $2^{\circ}$ del Código Penal (Decreto Legislativo $N^{\circ} 635,1991$ ) modificado por la (ley 30076), el Ministerio público convoca a los participantes del accidente de tránsito para la aplicación del Principio de Oportunidad. Lo cual implica una solución del conflicto previa a la formalización de denuncia penal en contra de quienes resulten responsables. Recuérdese que la responsabilidad penal también es solidaria, por lo que en estos casos, la empresa propietaria de la unidad que ha intervenido en el accidente de tránsito podría ser comprendida en el proceso en la calidad de tercero civilmente responsable. Con lo cual el representante legal de la empresa tendrá que comparecer ante las notificaciones y ante la audiencia de aplicación de Principio de Oportunidad.

Decimos que esta etapa es importante, por cuanto de manera definitiva de puede poner fin a la controversia penal por medio de un acuerdo repatorio con el agraviado o los herederos de la víctima. De acuerdo al Nuevo Código Procesal Penal, el acuerdo reparatorio puede ser invocado desde la ocurrencia del ilícito penal (accidente de tránsito con daños personales). Sin embargo, consideramos que un acuerdo preliminar puede presentar riesgos en la transacción. Por cuanto, no se podría realizar una razonable estimación del costo del tratamiento de las lesiones y por otra parte, la correcta identificación de los herederos; puede darse el caso en el cual los herederos posiblemente no hayan tramitado la sucesión intestada. Lo cual nos ayuda a eliminar riesgos y futuros reclamos por parte de un tercero que aduzca también tener la condición de heredero.

Lo recomendable en estos casos, con la finalidad de evitar una contingencia penal para la empresa, se recomienda transigir tanto la responsabilidad civil y penal mediante un acuerdo extrajudicial que puede ser utilizado para archivar la Investigación Preliminar, de esta manera se cierra el conflicto mediante el pago de una compensación, la cual puede ser calculada en atención al grado de participación del conductor de la empresa. En caso que la otra parte, los agraviados, exijan como reparación del daño una suma excesiva, podría atribuírsele su participación y colaboración en la generación del accidente a fin que reconsideren o disminuya su pretensión en atención a las faltas contra el RNT. Para 
esto resulta importarte que el agraviado internalice sus costos de llegar a un proceso judicial y considere que le resulta más satisfactorio solucionar la contienda en un corto plazo.

\subsection{Proceso penal por accidente de tránsito.}

En los accidentes de tránsito se pueden cometer dos tipos de ilícitos penales: 1) lesiones culposas agravadas, según el cuarto párrafo del artículo 124 del Código Penal (Decreto Legislativo $\left.\mathrm{N}^{\circ} 635,1991\right)$, y 2) Homicidio Culposo, según lo previsto por el artículo 111 del Código Penal (Decreto Legislativo N 635, 1991).

En el proceso penal se determinará si existe responsabilidad del conductor/es participantes en un accidente de tránsito. De acuerdo al RNT, el hecho que el conductor involucrado haya sido sancionado en sede administrativa por medio de una infracción de tránsito (papeleta) no implica ya no sea comprendido en un proceso penal:

Artículo 308.- Responsabilidad civil y penal.

Las sanciones establecidas en el presente Reglamento no excluyen la responsabilidad civil y penal a que hubiere lugar.

Por lo que en caso que no se haya solucionado el conflicto durante la investigación preparatoria, vía Principio de Oportunidad (acuerdo reparatorio), el Ministerio Público a través de su representante formalizará la denuncia penal que corresponda. En el contenido de la denuncia, el fiscal puede proponer las medidas coercitivas correspondientes al conductor, así como las medidas de embargo para asegurar el cumplimiento de una posible reparación civil. Además, conforme a lo previsto por (el artículo $100^{\circ}$ del Código de Procedimientos Penales), cuando la responsabilidad civil recaiga además del inculpado sobre terceros, estos deberán ser citados y tendrán derechos para intervenir en todas las diligencias que las afecten a fin de ejercitar su defensa. Por lo que el representante legal de la empresa involucrada tendrá que asistir cuantas veces sea necesaria a comparecer ante el proceso penal. Además, se debe tener presente el artículo 95 del Código Penal (Decreto Legislativo $\left.N^{\circ} 635,1991\right)$ ) señala:

Artículo 95.- Responsabilidad solidaria

La reparación civil es solidaria entre los responsables del hecho punible y los terceros civilmente obligados 
Durante el proceso penal, un punto importante es si la parte agraviada del accidente de tránsito se constituye como parte civil durante el proceso penal. Como señalamos en el punto anterior, resulta importante si en la etapa de Principio de oportunidad se transige el caso mediante una transacción que fije una reparación tanto civil y penal para los efectos del art artículo $2^{\circ}$ del Código Penal (Decreto Legislativo $\mathrm{N}^{\circ}$ 635, 1991) modificado por la ley 30076. Por cuanto de esta manera se cierra cualquier posibilidad que el agraviado, una vez que ha recibido la compensación insista su reclamo por la vía civil. Por este motivo, una vez declarada la constitución como parte civil, mediante resolución, el agraviado ya no podrá ejercitar su pretensión en la vía del proceso civil.

Para estos efectos, resulta pertinente tener en consideración lo señalado en la (Casación 196-2010 - Lima, 2011) :

[...] el Colegiado Superior mediante sentencia [...] la revoca y, reformándola, la declara infundada; sin costas ni costos, considerando que en el caso de autos existe una fractura causal, toda vez que el daño causado no ha sido consecuencia del actuar negligente o imprudente del conductor del vehículo sino del actuar propio de la víctima, Eusebio Moscoso López, no acarreándole responsabilidad civil a cargo del autor. Que no habiéndose acreditado responsabilidad alguna del demandado José Antonio Llabres Combina, ni responsabilidad vicaria de los otros codemandados, la demanda no merece amparo $[\ldots]$

[...]Que, en el caso de autos se advierte que el Ad quem, al emitir la sentencia de vista ahora impugnada, no ha dado estricto cumplimiento al principio contenido en el numeral glosado, por cuanto se ha limitado a valorar el expediente penal que obra como acompañado, sobre el delito contra la vida, el cuerpo y la salud, homicidio culposo, en agravio de Eusebio Moscoso López, omitiendo valorar los demás medios probatorios. $[\ldots]$

[...]Cabe Manifestar que el proceso de los debe contraerse a determinar si existe o no responsabilidad civil por parte de José Antonio Llabres Combina y demás demandados, como consecuencia del accidente de tránsito ocurrido [...] como consecuencia del cual falleció Eusebio Moscoso López, lo cual es distinto de investigar si al mencionado chofer debe o no atribuírsele responsabilidad penal en mérito a las consecuencias del accidente. Por consiguiente, el hecho de que no se le encuentre responsabilidad penal no implica necesariamente que no tenga responsabilidad civil, puesto que ambos son procesos distintos, cuidando de no emitir sentencias contradictorias. 
De la casación citada, podemos primero rescatar que resulta procedente que el agraviado acuda a la sede civil para reclamar una indemnización por daños y perjuicios como consecuencia del accidente de tránsito. Lo importante de esta sentencia, es que señala que en el proceso civil se realiza un nuevo estudio de los medios probatorios, y en el caso mencionado la Sala civil incurre en error al determinar que no existe responsabilidad civil por cuanto en la sentencia penal definitiva se declaró inocente al procesado. Para la Corte Suprema, se ha incurrido en causal de nulidad por cuanto la Sala para determinar la responsabilidad civil no sólo se debe analizar la sentencia penal definitiva o el resultado del proceso penal; sino por el contrario, se debe analizar todos los elementos probatorios de los cuales se pueda determinar si corresponde atribuir el daño o se ha incurrido en una fractura del nexo causal. Agregando, que el hecho de que no se le encuentre responsabilidad penal al conductor no implica necesariamente que no tenga responsabilidad civil, puesto que ambos son procesos distintos.

Por otro lado tenemos, lo señalado en la (Casación 1722 - 2009 - Lima, 2010):

[...] Si bien es cierto que el codemandado [...] no fue condenado por delito culposo en la vía penal, fue en aplicación del principio in dubio pro reo, teniendo el proceso penal como finalidad la protección de un bien jurídico (el derecho a la vida) en comparación con el principio de responsabilidad objetiva el cual sanciona la responsabilidad por manejar un bien riesgoso, según el artículo mil novecientos setenta del Código Civil, pues, la actividad siempre riesgosa de conducir vehículos de motor requiere en todo momento de parte de quien lo realiza un especial cuidado y máxima atención.

De lo anterior resulta claro, que el hecho que el conductor sea absuelto o condenado en sede penal, no implica que la contingencia se haya acabado o que el reclamo por parte de los agraviados haya cesado. Los agraviados en caso que no se constituyan como parte civil en el proceso penal, podrían interponer un proceso civil para reclamar la reparación civil. Situación que a todas luces incrementaría los costos a la empresa y la conduce al riesgo de ser pasible a ser obligada al pago de indemnizaciones elevadas, tal como veremos a continuación. 


\section{CAPÍTULO II: CONTINGENCIA EMPRESARIAL FRENTE A LOS ACCIDENTES DE TRÁNSITO CON DAÑOS PERSONALES}

\subsection{Responsabilidad del propietario}

En principio resulta válido cuestionar hasta donde alcanza la responsabilidad de la empresa propietaria de un vehículo. Conforme se ha señalado precedentemente, en nuestra legislación el propietario registral de un vehículo automotor en los procesos por accidentes de tránsito tendrá la condición de tercero civilmente responsable. Pero que sucedería en el caso, que nuestro colaborador Carlos Lescano, confiando de haberse salvado en reiteradas oportunidades de ser despedido, detiene su vehículo, mantiene el motor encendido con la llave de contacto en el vehículo de la empresa, y desciende del mismo para acercarse a un kiosko de periódicos donde se relatan los accidentes de tránsito de la ciudad. Por su descuido, una persona sube a la unidad y escapa con el vehículo. En su fuga, el vehículo ocasiona diversos accidentes de tránsito con daños personales. Ante este escenario, resulta pertinente cuestionar si por estos hechos también será comprendida la empresa como tercero civilmente responsable.

Con relación al propietario responsable, DE TRAZEGNIES (2005) nos conduce a abordar a la idea que es el propietario quien puede y se encuentra en una mejor posición, como por ejemplo contratar un seguro SOAT o un seguro de responsabilidad civil contra terceros:

283. Nuestra posición. Desde la perspectiva de la difusión del peso económico del daño que hemos adoptado en este libro como opción prioritaria (para el tratamiento de los accidentes), esta última interpretación que responsabiliza al propietario sería interesante, siempre que se tuviera en cuenta cuando se trate de juzgar los distintos casos, que el fin último es efectivamente la difusión del riesgo y no una suerte de responsabilidad ciega del presunto propietario.

Decimos que la interpretación es interesante porque usualmente es el propietario quien se encuentra en mejor aptitud para utilizar ese poderoso mecanismo difusor que es el seguro. (p. 500). 
Podemos comentar lo señalado, al recalcar la importancia de los seguros en relación a los accidentes de tránsito. Notaria es la importancia de contar con un seguro de responsabilidad civil contra terceros. Pues estos permiten asegurar el patrimonio de la empresa. Tal como lo señala BERDEJO, (2016), con relación al seguro de responsabilidad civil: "Es aquel Seguro [sic] mediante el cual el asegurador se obliga a mantener indemne el patrimonio del asegurado, cuando este último deba afrontar una obligación de Responsabilidad Civil por daños que hubiere causado a oras personas." (p. 309) .

Tal es así que en el supuesto que el vehículo haya sido robado y se haya ocasionado lesiones con el mismo vehículo en la vía pública. La póliza de responsabilidad civil y la póliza SOAT cubrirían los gastos de atención médica y otros. La misma ley no hace una distinción o precisión si el accidente de tránsito se produce con motivo de un robo. Tal como lo hace la legislación española. Conforme, DE DIOS (2012) nos detalla los supuestos en los cuales el propietario registral deja de ser responsable y no se le aplica el artículo 120.5 del Código Penal (Decreto Legislativo $\mathrm{N}^{\circ} 635,1991$ ) español que establece la responsabilidad civil subsidiaria derivada del delito o falta, imputable la responsabilidad al propietario no conductor por el mero hecho de la propiedad del vehículo, susceptible de crear riesgos para terceros:

- Cuando el vehículo haya sido robado. Con la entrada en vigor de la Ley 21/20007, de RVSCVM, se ofrece una nueva aclaración sobre el concepto de robo. Así el art. 11.1.c) establece que corresponde al CCS, dentro del ámbito territorial y hasta el límite cuantitativo del aseguramiento obligatorio, indemnizar los daños a las personas y en los bienes ocasionados por un vehículo con estacionamiento habitual en España que no esté asegurado y haya sido objeto de robo o robo de uso. El art. 8 del RD 1507/2008, de 12 de diciembre, por el que se aprueba el RSORCCVM, entiende como vehículo robado las conductas tipificadas como robo y robo de uso en los art. 237 y 244 del CP.

- En los supuestos en los que se haya producido una cesión indefinida del vehículo a otra persona. Supuesto en el que existe una renuncia abdicativa o abandono de uso del automóvil, usufructo, leasing o venta con pacto de reserva de dominio. (p. 88)

El texto citado, nos permite abordar a otros supuestos en los cuales el propietario registral, no necesariamente resultaría ser comprendido como tercero civilmente responsable en un proceso. Tal como veremos más adelante. Sin embargo, esta contingencia empresarial se 
eliminaría con la contratación de un seguro vehicular de responsabilidad civil el cual podría cubrir los daños ocasionados con motivo de un accidente de tránsito.

No cabe duda que si la empresa mantiene asegurados los vehículos de su propiedad, se reducirán los costos de transacción. Por cuanto como asegurado, puede solicitar que la compañía de seguros en atención a la póliza de responsabilidad civil cubra la solicitud de indemnización por parte de los agraviados. BERDEJO (2016), nos comenta sobre esto, señalando:

[...] en aquellos casos que la responsabilidad del asegurado sea evidente se da la oportunidad al asegurador de tratar de indemnizar a la víctima a través de una transacción extajudicial, evitando costos de litigio innecesario y cumpliendo además el Seguro de Responsabilidad Civil una importante función social.(p. 312)

En su función, como gestión de reparación del daño resulta importante que al indemnizar a la víctima, la compensación otorgada sea total y definitiva, y esta suponga la reparación de daños en lo civil y penal. Para lo cual se recomienda, insertar en la transacción extrajudicial las siguientes clausulas:

Primero.- Por el presente documento, LAS PARTES, con el propósito de finiquitar todas las pretensiones que se deriven o pudieran derivar del citado accidente, acuerdan en transigir totalmente la responsabilidad civil y/o penal que pudiera haberse generado, acordando el pago a favor del señor CARLOS LESCANO ROMERO por el monto de S/ 400 ( Cuatrocientos y 00/100 nuevos soles). Por lo que LAS PARTES acuerdan que no tienen nada que reclamarse mutuamente, producto del mencionado accidente de tránsito, ni en el presente ni en el futuro, ya sea en la vía civil, penal o administrativa. Poniendo fin en forma definitiva a todas las diferencias, discrepancias, disputas y/o controversias, respecto a los daños personales y materiales generados con ocasión al referido accidente. Segundo.- LAS PARTES renuncian de manera irrevocable a entablar cualquier acción o excepción tendiente a modificar, anular, desconocer, impugnar, resolver o rescindir la presente transacción. De esta manera, LAS PARTES reconocen expresamente que los términos acordados en la cláusula segunda del presente documento incluyen a su vez el Daño Emergente, Lucro Cesante, Reparación Civil, Daño Moral y/o Daño a la Persona, razón por la cual, LAS PARTES no podrán iniciar acciones legales por dichos conceptos en la vía penal, civil o administrativa.

Tercero.- LAS PARTES transigen la responsabilidad que pudiera haberse derivado como consecuencia del accidente de tránsito; con la finalidad ARCHIVAR 
DEFINITIVAMENTE el proceso por faltas que pudiera iniciarse en aplicación del artículo 7 de la Ley $\mathrm{N}^{\circ} 27939$.

Cuarto.- LAS PARTES acuerdan que el presente documento Extrajudicial se celebra también para los efectos de la APLICACIÓN DEL PRINCIPIO DE OPORTUNIDAD, de conformidad con lo dispuesto en el artículo $2^{\circ}$ del Código Procesal Penal, modificado por Ley $\mathrm{N}^{\circ} 30076$, y demás normas vigentes.

Quinto.- LAS PARTES declaran conocer que de conformidad con los artículos $1302^{\circ}$ y $1303^{\circ}$ del Código Civil la presente transacción tiene valor de COSA JUZGADA por lo que las partes renuncian irrevocablemente a ejercer cualquier acción o deducir excepción alguna tendiente a modificar, anular, resolver o rescindir la presente Transacción Extrajudicial; asimismo, las partes pactan en contrario de lo dispuesto por el primer párrafo del artículo $1310^{\circ}$ del Código Civil.

De esta manera, la transacción extrajudicial celebrada con el agraviado resulte efectiva a nivel policial, investigación preliminar penal y proceso civil.

\subsection{Responsabilidad del arrendatario financiero.}

Con relación al arrendamiento financiero (Contrato de Leasing), este se encuentra regulado por el (Decreto Legislativo $\mathrm{N}^{\circ}$ 299). En el cual mediante su artículo $11^{\circ}$ se establece que el bien materia de arrendamiento financiero no puede ser embargado vía administrativa y/o judicial.

Al respecto, también tenemos la (Casación 2025- 2013 - Lima, 2014), que ha determinado lo siguiente:

[...] El artículo 6 del Decreto Legislativo número 299, define que la arrendataria es responsable del daño que pueda causar el bien, desde el momento que lo recibe de la locadora; dicho artículo en realidad regla la responsabilidad extracontractual frente a terceros en el contrato de leasing, debiendo entenderse que quien debe responder por los daños a terceros es la empresa usuaria desde el momento en que toma posesión del bien otorgado en leasing pues atendiendo a la naturaleza jurídica de este tipo de contratos, lo contrario implicaría desincentivar su aplicación en nuestro sistema; e) El [sic] Banco no resulta responsable por el daño ocasionado a la demandante, sino que el juicio de responsabilidad debe efectuarse solo respecto de la empresa de Transportes Tenorio Empresa Individual de Responsabilidad Limitada, debiéndose declararse improcedente la demanda respecto de la entidad bancaria. 
Conforme a lo anterior, no nos queda dudas frente a un accidente de tránsito con un vehículo prestado en arrendamiento financiero, se podrá demandar como propietario a la empresa arrendataria, más no contra el arrendador financiero, que por lo general se trata de una entidad bancaria o una Sociedad Administradora de Fondo de Inversión (SAFI).

\subsection{Responsabilidad civil del dependiente}

Cuando citamos la (Casación 1852 - 2015 - Callao, 2016) arribamos a la conclusión que en el presente caso, al tratarse de un vehículo inmatriculado, no registrado, no se podía atribuir responsabilidad a la empresa por su condición de propietaria del bien; por lo contrario, la responsabilidad se puede atribuir al empleador del conductor al amparo del artículo 1981 del (Código Civil). Por lo tanto, tenemos que en ambos escenarios, tanto como propietario del vehículo automotor y como empleador del conductor, la empresa propietaria resultará comprendida como tercero civilmente responsable. Esto es de manera objetiva, tal como lo señala DE TRAZEGNIES, (2005, p. 518), cuando concluye que el acto del dependiente debe ser de tal naturaleza que se encuentre incurso en el régimen general de la responsabilidad extracontractual; por lo que no habría obligación del principal de indemnizar si previamente no existe un daño indemnizable. Por otra parte, arriba al cuestionamiento: “Ahora bien si el principal no responde por culpa, ¿qué es lo que justifica su responsabilidad?" (p. 519). Por cuanto, en los casos de accidentes de tránsito de acuerdo a la regulación la responsabilidad es objetiva por creación del riesgo.

No obstante lo anterior, tenemos razonamientos que se alejan de la doctrina y arriban a cargas subjetivas, como lo señala VALDIVIA (2017) comentando la sentencia penal en el caso penal en agravio de Ivo Dutra Camargo, señala:

[...] caso que fue judicializado en sede penal estableciéndose la reparación civil respectiva por haber infringido el bien jurídico (vida humana) ascendente a un millón de soles a favor de la parte civil. Asimismo, se estableció que dicha empresa de transporte es tercero civilmente responsable, debiendo asumir solidariamente también su pago, en razón de tener pleno conocimiento de las innumerables papeletas impuestas al sentenciado, así como por no efectuar una selección responsable de su personal, por el contrario contrató nuevamente de sus servicios como chofer profesional al sentenciado, poniendo en las calles y al 
volante a una persona que constituye un serio y grave peligro para la integridad personal física de la colectividad y que se ve materializado con el irreparable daño ocasionado. (p. 171).

En cuanto al monto de la reparación civil nos reservamos nuestro comentario para un análisis posterior. Pero no podemos dejar de advertir que si nos encontramos frente a un régimen de responsabilidad fundada en el riesgo creado. Resulta cuestionable que se señale que a la empresa de transporte se le atribuye responsabilidad por cuanto no fue diligente en la selección de su personal. El operador judicial no puede desviar su fundamentación en criterios subjetivos, por lo contrario, debe adecuarse a las formas contractuales entre el conductor de la unidad y el empleador. Por cuanto, el panorama laboral actual nos brinda una serie de modalidades contractuales que pueden excluir a una empresa de un proceso judicial tan solo por acreditar que no existe un vinculo laboral con el conductor.

Con relación al vinculo laboral de un trabajador quien falleció en un accidente de tránsito y laboraba para una empresa que brindaba servicio de seguridad a una empresa minera, procedemos a analizar la (Casación 4852-2012-Lima, 2013):

La cuestión jurídica materia de debate en esta sede Casatoria consiste en determinar si se ha infringido o no el artículo 1981 del Código Civil, esto es, si existe responsabilidad solidaria de la empresa minera por el accidente sufrido por uno de los trabajadores de la empresa que le prestaba servicios de seguridad.

[...] No es factible considerar la existencia de una relación de dependencia del personal de la empresa Orión con la Compañía Minera Poderosa S.A. por el solo hecho de la existencia de un supervisor que coordinaba la prestación de servicio de seguridad, conforme lo ha señalado la sentencia de segunda instancia; ya que la actividad de seguridad, resguardo no encaja de modo alguno dentro de la actividad principal de la empresa usuaria, que conforme se desprende se dedica a la actividad minera [...] "son actividades de industria minera, las siguientes: cateo, prospección exploración explotación, labor general, beneficio, comercialización y transporte minero". En ese orden de ideas, la responsabilidad de la empresa minera sólo podía extenderse a las labores que se realizan para las actividades antes indicadas, pero no para servicios conexos no mineros, en cuyas circunstancias las responsabilidad [sic] y obligaciones no tenía en carácter de solidarias, conforme las normas antes citadas y lo expuesto en el artículo 216 del Texto único Ordenado de La Ley General de Minería. 
Cabe agregar las actividades como seguridad y resguardo no son inherentes al objeto social de la empresa principal por cuanto esta por contrato prestaba servicio de vigilancia y resguardo. Nos encontramos conformes con la sentencia citada, pero distinta hubiera sido nuestra opinión en el caso que la empresa de resguardo y la empresa minera hayan mantenido un vinculo contractual con ocultar un vinculo laboral primigenio con la empresa minera. Pongámonos en el caso que el trabajador haya iniciado su vinculo laboral en la empresa y todo el personal de resguardo y seguridad haya sido trasladado a otra empresa aduciendo tercerización laboral. En el supuesto que en un tribunal laboral se acreditara la desnaturalización de contrato y la declaración de un único vinculo laboral. El trabajador o sus hederos hubieran tenido expedito su derecho para demandar a la primera empresa. Es por ello, que al inicio indicamos que el operador jurídico no debe ser ajeno a las leyes de índole laboral y las diversas modalidades de contratación para determinar la verdadera relación entre el conductor y su empleador.

Citemos algunos ejemplos para el debate:

- Un trabajador de una empresa que brinda servicio de Vallet Parking participa en un accidente de tránsito.

- Una empresa de comida rápida contrata un servicio de mensajería a una empresa que le brinda motorizados y motos para repartir la comida. Y una de estas motos participa en un accidente de tránsito.

- Una compañía de seguros: Lima Seguros, para brindar su servicio de asistencia mecánica y grúas contrata a una empresa vinculada al grupo económico llamada: Lima Asiste, para prestar el servicio con motorizados, autos y grúas que llevan consigo el logo de la compañía principal. Y uno de estos vehículos participa en un accidente de tránsito.

- Un chofer de reemplazo de una empresa que brinda este servicio. Finalmente participa en un accidente con consecuencia fatal. ¿La empresa que lo colocó como chofer de la unidad participante será considerada responsable?

No podemos ser ajenos a la diversidad de negocios modernos. Por lo que volviendo a lo señalado por DE TRAZEGNIES (2005) quien nos resume su posición de la responsabilidad del principal, señalando lo siguiente: 
El principal responde porque, dado que realiza una actividad económica, tiene la posibilidad de difundir más fácilmente a través del sistema de precios el costo de estos accidentes inevitables que se presentan en todo proceso productivo de bienes y servicios. Por consiguiente, no es que el principal sea "culpable" [...] sino simplemente es el mejor vehículo para diluir estos costos sociales. Todos se benefician con la actividad productiva: el principal que tiene un beneficio, el servidor que tiene un emolumento, la sociedad que cuenta así con los productos que necesita, etc. Por consiguiente, todos deben compartir el peso económico de esos daños estadísticamente inevitables. (p. 524)

Frente a este razonamiento, podemos cuestionar si la responsabilidad puede llegar a atribuirse al servicio de taxi por aplicación vía Internet. A nuestro criterio, la empresa pese a haber limitado su responsabilidad con el conductor. No podemos distraer nuestra atención en señalar que es la empresa que colocó al conductor frente al agraviado o que la aplicación no reconoció que el conductor contaba con diversas papeletas que le impedían circular por la ciudad. No recomendamos analizar el caso en términos subjetivos; por ende, la empresa gestora de la aplicación de taxis por internet debería ser comprendida como tercero civilmente responsable porque es parte de la actividad económica que supone el negocio del taxi, emite recibos y boletas electrónicas, gestiona el cobro mediante tarjetas de crédito, y mediante la aplicación determina cual será la ruta a seguir en cumplimiento de su servicio. A la fecha, no tenemos una jurisprudencia en este tipo de casos, solo esperamos que no se emita una fundamentación vacilante y vaga que traiga consigo desalentar el uso de los taxis por aplicación.

Por lo contrario, la empresa de la aplicación como principal adoptará las medidas necesarias para continuar en el negocio, como por ejemplo: contratar un seguro contra terceros por responsabilidad civil. Tal como sucede en los casos de empresas que brindan servicio de Vallet Parking, o servicio de traslado de automóviles inmatriculados (sin placa de rodaje), con la llamada placa de exhibición que recién han sido desembarcados en puerto. En estos casos, el seguro de responsabilidad civil es contratado un función al conductor, el llamado "seguro de brevete" y este seguro se activará en caso que el chofer perjudique la unidad que conduce y/o ocasione daños a terceros.

En ese orden de ideas, frente a la regulación respecto a la responsabilidad del propietario o del principal, tenemos que resulta recomendable internalizar los costos del negocio operativo, y por medio del sistema de precios contar con un seguro de 
responsabilidad civil con la finalidad de evitar una contingencia contra el patrimonio empresarial.

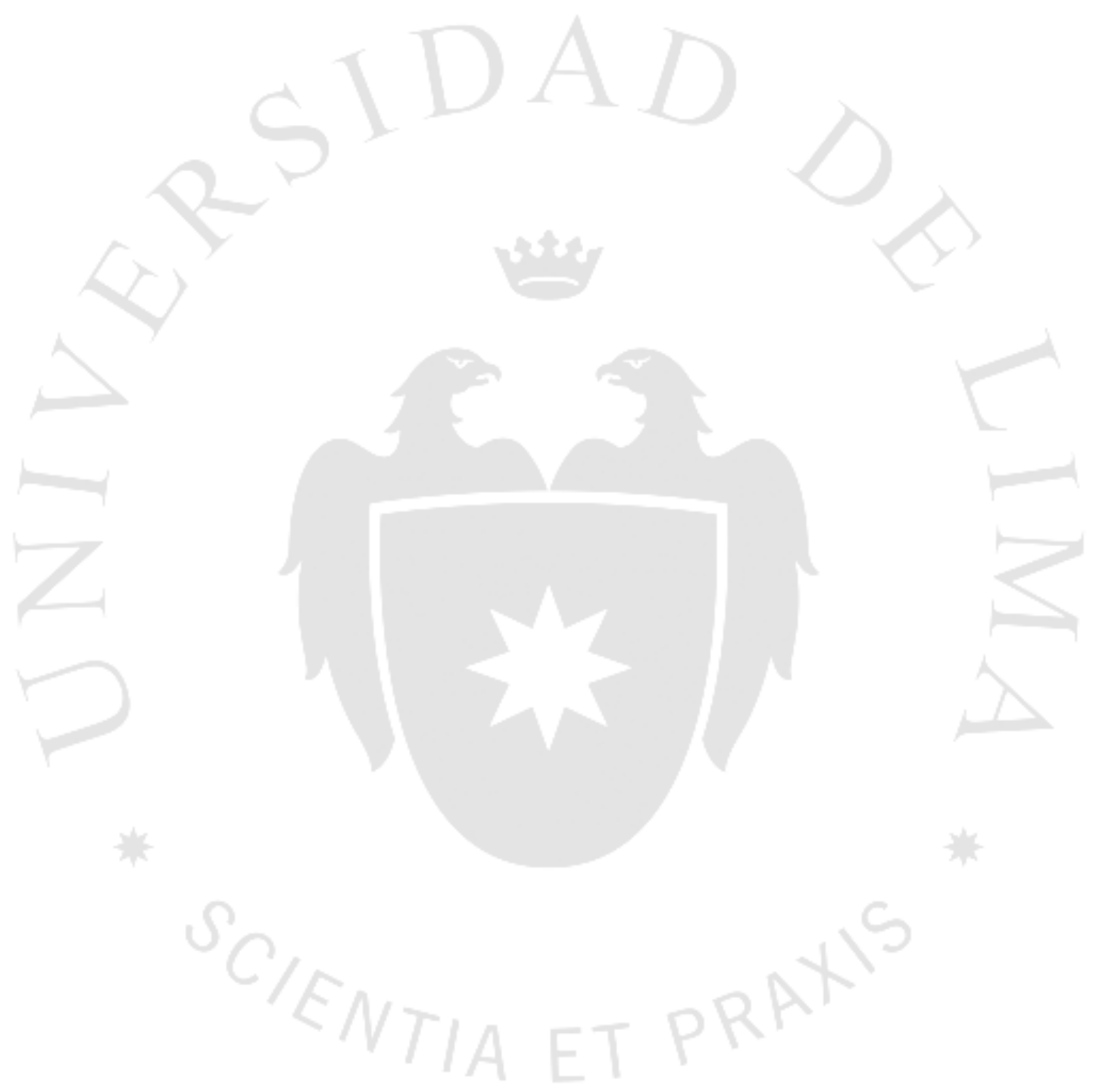




\section{CAPÍTULO III: RESARCIMIENTO DEL DAÑO PERSONAL}

\subsection{Cuantificación del daño personal}

Desde una postura empresarial, se recomienda solucionar los conflictos derivados de los accidentes de tránsito con daños personales en un corto plazo, o mientras dure la investigación preliminar. En su caso, mediante Principio de oportunidad. Eliminándose de esta manera la contingencia penal sobre el caso.

En el caso de lesiones personales la cuantificación del daño puede darse en atención a los costos que no cubiertos por el SOAT:

- Costo de atenciones médicas

- Costo de medicinas.

- Costo de estudios y análisis médicos (Laboratorio, Rayo X, Tomografías)

- Costo de transporte y traslado.

- Lucro cesante por el tiempo de incapacidad. (debidamente acreditado)

- Costos de asistencia (enfermera, ayudante, y alimentación)

- Costo por daños materiales (Vestido, calzado, bicicleta, silla de ruedas, celulares, computadoras, dispositivos electrónicos, audífonos para sordera, etc.)

La sumatoria de estos costos nos puede dar un monto como base para proponer como una formula conciliatoria. Estos costos pueden variar de acuerdo al grado de participación del conductor y el agraviado. De esta manera, las compañías de seguros también pueden fijar el quantum indemnizatorio a favor de los agraviados.

Sin embargo, el problema radica en los casos cuando la cobertura SOAT se agota inmediatamente sucedido el accidente, ya sea por el costo elevado del tratamiento o por el tipo de lesión, y el uso de la unidad de cuidados intensivos. En estos casos, si la empresa cuenta con una póliza de responsabilidad, puede solicitar a la compañía de seguros para la active para que el paciente pueda continuar su tratamiento hasta sacarlo de peligro. Si bien esto no puede considerarse, como parte de una indemnización, otorga al propietario 
de la unidad un mejor panorama para conciliar el caso. Adicionalmente, en sede penal el monto de la carta de garantía emitida por la asegurada puede ser tomado en cuenta al momento de resolver el caso mediante una sentencia que ordene el pago de una reparación civil.

No hay duda, con el sistema de seguro obligatorio SOAT la empresa no se verá en la obligación de costear los gastos de tratamiento de emergencia y atención de un agraviado. Tal como sucedería en un escenario donde no se cuente contratada la póliza SOAT. Ahora, en caso que el vehículo de la otra parte no cuente con SOAT. No es impedimento para que se active la póliza vehicular del vehículo de la empresa para aliviar la carga del agraviado de costear por si mismo su daño. Sobre todo, si estamos frente a un escenario donde hay evidente responsabilidad del conductor de la empresa. Por lo contrario, si hay evidencias que la responsabilidad recae en el otro conductor - sin SOAT, se recomienda esperar el resultado de la investigación preliminar para tomar una decisión sobre el caso.

\subsection{Panorama sobre la cuantificación del daño moral en los casos de homicidio culposo derivado accidentes de tránsito}

Como se puede apreciar, en cuanto al daño personal respecto a lesiones personales, estas pueden resarcirse de manera directa o por medio de un seguro de responsabilidad civil en función al tiempo de incapacidad. Todo esto en un corto plazo a fin de evitar una sentencia judicial. Pero los mayores cuestionamientos vienen en el caso de un accidente de tránsito con consecuencia fatal. De qué forma se puede resarcir el daño. Valdivia (2017) comentando la sentencia penal en el caso penal en agravio de Ivo Dutra Camargo, señala:

Se está cambiando la mentalidad por parte de los juzgadores al buscarse una reparación teniendo en cuenta la magnitud de los daños ocasionados. Esto se ha comenzado a generar en sede penal, considerándose para ello las reglas de la responsabilidad civil, como aconteció en el caso del desaparecido Ivo Johao Dutra Camargo, en la que se atendió la magnitud de los daños y perjuicios, considerándose el bien jurídico infringido (vida humana), dejándose de lado el criterio que se venía aplicando en sede penal de considerarse las posibilidades económicas del obligado para cuantificarse los daños, dándose con ello un buen mensaje a la sociedad. Lo mencionado evitaría que la víctima del accidente de tránsito tenga después que accionar en la vía civil para efectos de 
conseguir una indemnización por daños y perjuicios con un monto adecuado que repare integralmente los daños que se le han ocasionado. (p. 188).

Primero resulta pertinente cuestionar si una empresa podría soportar la carga de pagar y/o cumplir con su obligación de pagar un millón de soles. El abogado citado nos señala que estamos frente a un mensaje para la sociedad. A todas luces, es necesario que nos indique cuál es el verdadero mensaje hacía la empresa. Como vimos en la casación respecto al leasing, el operador jurídico no podría pretender desalentar el uso del contrato atípico; de la misma manera, en este caso, la Corte estaría desalentando la formación o creación de empresas de transporte. Acaso el Estado pretende volver al esquema de tener una empresa de transporte público y el dominio de todas las rutas de la ciudad. Consideramos que estamos frente a un Estado de Derecho que es respetuoso de las personas y personas jurídicas, sobre todo de la actividad empresarial privada, la cual con el ejercicio de una actividad riesgosa, transporte público, genera empleo y distribución de riqueza.

Nuestra posición dista mucho de lo señalado por Valdivia, por cuanto consideramos que a lo largo de diversas sentencias de la Corte Suprema, las indemnizaciones por daños y perjuicios con ocasión de un accidente de tránsito no son parte de una justicia con sentencias predictivas, todo lo contrario, nos encontramos frente a sentencias que no unifican criterios y establecen distintas formas de evaluar Quantun indemnizatorio. Si bien es cierto, en sede penal se valora la capacidad económica o ingreso mensual del conductor responsable, una indemnización por fallecido oscila en la actualidad en veinte cinco mil nuevos soles a treinta mil nuevos soles. El monto resulta predictivo, en toda la sede penal, pero puede reducirse en atención al grado de participación de la víctima y podría incrementarse en atención al concurso de otros ilícitos penales, como por ejemplo: conducción en estado de ebriedad, abandono y exposición de personas en peligro.

No obstante la configuración de estos dos ilícitos penales, el sistema de seguros otorga al empresario librarse de la responsabilidad ocasionada por un empleado a todas luces irresponsable. La responsabilidad civil en estos casos puede ser cubierta con la póliza a todo riesgo, o llamada "ausencia de control". La cual implica la cobertura de la reparación civil en los casos en los cuales el empleador no puede o no está en la posición de controlar a sus dependientes en este tipo de situaciones.

Como por ejemplo, nuestro colaborar Carlos Lescano, luego de una jornada laboral con el vehículo de la empresa decide libar licor con su ayudante, luego de haber 
ingerido suficiente licor como para mofarse de los diversos casos de los cuales fue absuelto, decide circular con el vehículo de la empresa y ocasiona un accidente con consecuencia fatal. Carlos temeroso que esta vez terminará en la cárcel decide abandonar el lugar, dejando la unidad en el lugar del accidente. A las pocas horas, Carlos es atrapado y puesto a disposición de la policía.

En caso que la empresa haya contratado una póliza a todo riesgo con ausencia de control, se permite la cobertura en caso que el conductor no supere el límite establecido en la póliza. Por lo general el límite es $1.00 \mathrm{ml}$. En caso que se supere el limite, el caso no tendrá cobertura para la atención de los agraviados. Lo que supone que la empresa responderá civilmente con su patrimonio. Caso contrario, sucede en los casos de fuga del conductor, en esos casos, la cobertura no está sujeta a algún tipo de condición respecto al conductor.

Como vemos, los seguros mantienen su cobertura ante el ilícito penal ocasionado con motivo de un accidente de tránsito. En su defecto, la empresa será solidaria con relación al pago por reparación civil en sede penal.

La dación de una sentencia que establezca como monto indemnizatorio por la suma de un millón de soles, resulta ilusoria e irrazonable. Si se tiene en consideración el criterio establecido en la (Casación 1164-2015-Junín, 2016) en un caso donde la segunda instancia declaró fundada en parte la demanda y fijo el monto de S/ 30,000.00 por concepto de daño moral por fallecimiento. La Corte Suprema señala que la sala no justifica adecuadamente en qué valoración o en cuál o cuáles medios probatorios aportados en el proceso sustenta su parte resolutiva, o en su defecto en qué consideraciones jurídico doctrinarias y jurisprudenciales se sustenta su decisión de otorgar sólo el monto de S/. 30,000. Por lo que declara nula la sentencia emitida en segundo grado. Ordenándose a esta instancia emitir nuevo pronunciamiento.

Este es el razonamiento que se espera de un operador jurídico, en el cual se exija una debida motivación con relación al quantum indemnizatorio. Reiteramos nuestra posición en contra a las sentencias emitidas por el órgano jurisdiccional sin un mínimo análisis de los medios probatorios del caso exijan el pago de sumas millonarias, a todas luces irrazonables y desproporcionales, las cuales resultan acorde a la realidad económica del país, sobre todo se genere un sobrecosto a las empresas vinculadas al transporte y aquellas empresas que por medio de la utilización de vehículo automotores concluyan 
que trabajar con vehículos automotores supone un grave riesgo para la empresa. Entendemos que la vida no tiene precio, pero esta debe ser compensada de acuerdo a fórmulas que permitan equidad y predictibilidad en el monto indemnizatorio. Como por ejemplo la cuantificación que se ha fijado vía (Decreto Supremo No 015-2013-MTC, publicado el 15 noviembre 2013, Reglamento Nacional de Responsabilidad Civil y Seguros Obligatorios de tránsito), en cuanto a la compensación por fallecimiento en la suma equivalente a 4 UIT, calculada a la fecha del presente trabajo, en S/ 15,400. Siendo nuestra recomendación por medio de este trabajo que este valor sea actualizado y precisado en 8 UIT, monto que resulta equivalente al monto otorgado por medio de una sentencia promedio emitida en sede penal.

De esta manera, los herederos serán quienes luego de un análisis costo - beneficio puedan arribar a una transacción extrajudicial que satisfaga, en alguna medida, la pérdida de un ser querido. Para esto es importante la precisión del término "casual" en la definición de accidente de tránsito. Por cuanto la misma regulación de tránsito debe extender un mensaje que estamos frente a hechos casuales, revistos de culpabilidad, no deseados por la sociedad, y que de alguna manera pueden resarcirse por medio de un acuerdo reparatorio conforme lo promueven la regulación penal. 


\section{CONCLUSIONES}

- Un accidente de tránsito puede ser considerado como un evento casual en el cual participa por lo menos un vehículo automotor y con motivo de la circulación ocasiona daños materiales y/o personales.

- La responsabilidad de los accidentes de tránsito es objetiva, por creación del riesgo, con la utilización de un vehículo automotor.

- Un accidente de tránsito se configura cuando se produce un despiste de una unidad de tránsito, o cuando se ocasiona daño mediante un impacto entre dos a más unidades de tránsito. Asimismo, cuando una unidad de tránsito impacta a una persona o más personas que circula como peatón. En ese orden de ideas, no podríamos estar frente a un accidente de tránsito en un hecho accidental donde no se logra consolidarse un impacto.

- La policía en la etapa de investigación preliminar realiza informes con elementos cargados de subjetividad que ocasionan criterios alejados de las sentencias emitidas en sede judicial.

- Es recomendable transigir el daño personal en la etapa de Aplicación de Principio de Oportunidad por cuanto de esta manera se elimina la contingencia penal. Asimismo, de lograrse una transacción extrajudicial en esta etapa se podría transigir también la responsabilidad civil. En cuanto al daño personal respecto a lesiones personales, estas pueden resarcirse de manera directa o por medio de un seguro de responsabilidad civil en función al tiempo de incapacidad. Todo esto en un corto plazo a fin de evitar una sentencia judicial.

- Reiteramos nuestra posición en contra a las sentencias emitidas por el órgano jurisdiccional sin un mínimo análisis de los medios probatorios del caso exijan el pago de sumas millonarias, a todas luces irrazonables y desproporcionales, las cuales resultan acorde a la realidad económica del país, sobre todo se genere un sobrecosto a las empresas vinculadas al transporte y aquellas empresas que por medio de la 
utilización de vehículo automotores concluyan que trabajar con vehículos automotores supone un grave riesgo para la empresa.

- Un accidente de tránsito puede ser considerado como un evento casual en el cual participa por lo menos un vehículo automotor y con motivo de la circulación ocasiona daños materiales y/o personales.

- La responsabilidad de los accidentes de tránsito es objetiva, por creación del riesgo, con la utilización de un vehículo automotor.

- Un accidente de tránsito se configura cuando se produce un despiste de una unidad de tránsito, o cuando se ocasiona daño mediante un impacto entre dos a más unidades de tránsito. Asimismo, cuando una unidad de tránsito impacta a una persona o más personas que circula como peatón. En ese orden de ideas, no podríamos estar frente a un accidente de tránsito en un hecho accidental donde no se logra consolidarse un impacto.

- La policía en la etapa de investigación preliminar realiza informes con elementos cargados de subjetividad que ocasionan criterios alejados de las sentencias emitidas en sede judicial.

- Es recomendable transigir el daño personal en la etapa de Aplicación de Principio de Oportunidad por cuanto de esta manera se elimina la contingencia penal. Asimismo, de lograrse una transacción extrajudicial en esta etapa se podría transigir también la responsabilidad civil. En cuanto al daño personal respecto a lesiones personales, estas pueden resarcirse de manera directa o por medio de un seguro de responsabilidad civil en función al tiempo de incapacidad. Todo esto en un corto plazo a fin de evitar una sentencia judicial.

- Reiteramos nuestra posición en contra a las sentencias emitidas por el órgano jurisdiccional sin un mínimo análisis de los medios probatorios del caso exijan el pago de sumas millonarias, a todas luces irrazonables y desproporcionales, las cuales resultan acorde a la realidad económica del país, sobre todo se genere un sobrecosto a las empresas vinculadas al transporte y aquellas empresas que por medio de la utilización de vehículo automotores concluyan que trabajar con vehículos automotores supone un grave riesgo para la empresa. 


\section{RECOMENDACIONES}

A continuación detallaremos las recomendaciones:

- La regulación de tránsito debe apuntar a la prevención de accidentes con daños personales. Asimismo se recomienda definir el accidente de tránsito como un hecho casual, para que los ciudadanos consideren la posibilidad de transigir estos daños con la intención de descongestionar el Poder Judicial de demandas por daños. 


\section{REFERENCIAS}

Berdejo (2007). La responsabilidad civil derivada de los accidentes de tránsito. En Actualidad Jurídica № 159. Gaceta Jurídica.

Berdejo (2016). El Seguro de Responsabilidad Civil en la Ley de Contrato de Seguro. En Revista Advocatus $\mathrm{N}^{\circ}$ 31. Revista editada por los Alumnos de la Facultad de Derecho de la Universidad de Lima.

Daray (2001). Derecho de Daños en Accidentes de Tránsito: doctrina y jurisprudencia sistematizada. Tomo I. Buenos Aires. Editorial Astrea.

De Trazegnies (2015). La Responsabilidad Extracontractual. Vol. IV - Tomo I. Biblioteca Para Leer el Código Civil. Fondo Editorial de la Pontificia Universidad Católica del Perú.

De Dios (2012). Culpa Exclusiva De La Víctima En Los Accidentes De Circulación. Las Rosas, Madrid. Editorial La Ley.

Valdivia (2017). Aspectos relevantes en la responsabilidad civil derivada de los accidentes de Tránsito. En Revista Actualidad Civil. Instituto Pacifico. 